\title{
Colitis: an unusual presentation of Wegener's granulomatosis
}

\author{
Joseph Dalby Sinnott, ${ }^{1}$ Paul Matthews, ${ }^{2}$ Simon Fletcher ${ }^{3}$
}

${ }^{1}$ General Medicine, Warwick Hospital, SWFT, Warks, UK ${ }^{2}$ Department of Histopathology, UHCW, Coventry, UK

${ }^{3}$ Department of Renal and Transplant, UHCW, Coventry, UK

Correspondence to Dr Joseph Dalby Sinnott, j.d.sinnott@gmail.com
To cite: Sinnott JD, Matthews P, Fletcher S. BMJ Case Rep Published online: [please include Day Month Yearl doi:10.1136/bcr-2012007566

\section{SUMMARY}

Wegener's granulomatosis (WG) also known as granulomatosis with polyangiitis (GPA) is an antineutrophil cytoplasmic antibody-positive (ANCA) vasculitis which most commonly affects the upper respiratory tract, lungs and kidneys. It is uncommon for colitis to be the primary reason for the first hospital admission related to WG. This case represents one of the few in the literature where colitis is associated with WG and in particular, where colonic involvement was the presenting symptom. The patient presented to hospital with a 3-day history of bloody diarrhoea and was treated for colitis. The disease progressed and during the second admission renal and pulmonary involvement was found. A renal biopsy showed a crescentic change and a CT-confirmed inflammatory changes in the caecum and ascending colon. A diagnosis of WG was made and appropriate treatment initiated. The patient is now in remission.

\section{BACKGROUND}

Wegener's granulomatosis (WG) is an antineutrophil cytoplasmic antibody (ANCA)-positive vasculitis affecting small- to medium-sized vessels. It is characterised by necrotising granulomas and most commonly affects respiratory tract and kidneys. Postmortem studies have displayed gastrointestinal involvement ${ }^{1}$ but colitis as a clinical feature is uncommon. This case represents one of the few where colitis is the primary reason for initial presentation to a hospital.

\section{CASE PRESENTATION}

A 29-year-old man presented to the accident and emergency department with a 2-day history of bloody diarrhoea. The blood was red and mixed with the stool. The diarrhoea was watery in nature, occurred 10-15 times a day and contained mucus. At the time of admission the patient had been experiencing symptoms of nasal congestion and lethargy for 2 months. There was no history of gastrointestinal problems and no family history.

There was no shortness of breath, cough or haemoptysis and clinical examination of the respiratory system was unremarkable.

Colitis caused by infection or inflammatory bowel disease was suspected and a series of blood tests were ordered. They showed a slightly raised white cell count $\left(15.24 \times 10^{9} / 1\right)$ with raised neutrophils $\left(11.16 \times 10^{9} / 1\right)$ and monocytes $\left(2.00 \times 10^{9} / 1\right)$. $\mathrm{He}$ also had a microcytic anaemia (mean corpuscular volume (MCV) $60.3 \mathrm{fl}$ ) (haemoglobin $8.7 \mathrm{~g} / \mathrm{dl}$ ) and raised inflammatory markers (C reactive protein $301 \mathrm{mg} / \mathrm{l}$, erythrocyte sedimentation rate $109 \mathrm{~mm} /$ hour). The urea was within the normal range (urea $5.1 \mathrm{mmol} / \mathrm{l}$ ), but creatinine was slightly high (creatinine $103 \mathrm{umol} / \mathrm{l}$ ). Stool microscopy and cultures were negative (see Investigations for details).

A cytoplasmic ANCA (cANCA) test was positive. Flexible sigmoidoscopy showed some patchy mild erethema within the rectum but the mucosa in the sigmoid was not obviously inflamed. Biopsies showed no evidence of granuloma formation. No chest $\mathrm{X}$-ray was performed during this initial admission. The patient was started on oral steroids owing to suspected inflammatory bowel disease and the symptoms improved. He was discharged with a gastroenterology follow-up arranged.

Two weeks later the patient developed diffuse abdominal pain with bloody diarrhoea very similar in nature to the previous episode. The patient also had fever, arthralgia and dyspnoea. A CT of the abdomen was performed which showed inflammatory changes in the caecum and ascending colon. At this admission there was also obvious renal involvement with a markedly raised creatinine $(388 \mu \mathrm{mol} /$ 1). Protinase-3 (PR3) antibodies were high (24 kU/l). The lower respiratory tract was also involved. A chest x-ray showed bilateral costophrenic blunting with some indication of mild pulmonary congestion. A CT scan significantly demonstrated a ground glass appearance in the lung bases.

A renal biopsy showed the presence of a crescentic glomerulonephritis (figure 1) which was consistent with a diagnosis of WG. These results combined with a more detailed history which elicited the fact the patient had experienced epistaxis twice in the last month led to the diagnosis of WG.

The patient was admitted to the renal ward where he received plasma exchange therapy, corticosteroids and pulsed intravenous cyclophosphamide. After 10 days in the ward he was able to go home with him coming back for a last dose of cyclophosphamide.

\section{INVESTIGATIONS \\ Serology}

cANCA was positive. Protinase-3 antibodies $24 \mathrm{kU} / \mathrm{l}$. Stool microscopy and cultures: Negative for cryptosporidium, Escherichia coli O157, Campylobacter, Salmonella, Shigella and Clostridium difficile. Sigmoidoscopy: Small amount of inflammation observed in rectum. No obvious abnormality seen the in sigmoid colon. Rectal biopsy: no granuloma or inflammatory change. 


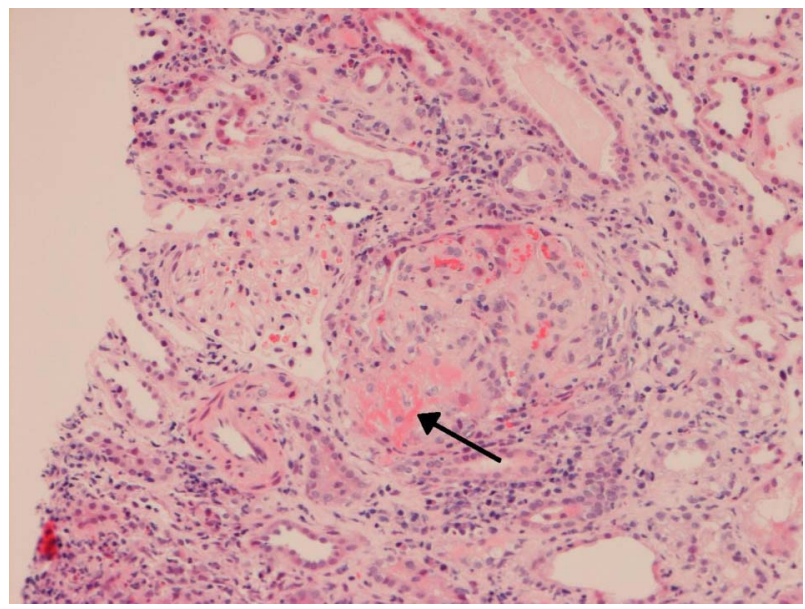

Figure 1 The arrow highlights a segmental necrotising lesion. The adjacent glomerulus is relatively normal.

\section{CT scan}

Inflammatory change in caecum and ascending colon. Ground glass appearance of lung bases was observed. A renal biopsy was performed and the results are shown in figure 1. A segmental necrotising lesion with a crescentic formation is shown. The majority of glomeruli seen on biopsy showed this histological pattern. This is consistent with the expected findings in WG with renal involvement.

\section{OUTCOME AND FOLLOW-UP}

Once a diagnosis of WG was made upon the second admission, appropriate treatment with corticosteroids was initiated immediately. Owing to the extent of the renal involvement by this time, it was decided that plasma exchange was also appropriate. The patient received pulsed intravenous cyclophosphamide and made a good recovery.

He was then sent home with oral medications and outpatient follow-up. He is currently in remission.

\section{DISCUSSION}

WG is a multi-system disease most commonly affecting the upper respiratory tract, kidneys and lungs. A number of studies and case reports have shown that WG has a wide variety of presenting symptoms covering multiple systems. ${ }^{2-4}$ Colitis is a relatively uncommon sign and it is particularly uncommon for colitis to be the primary reason for the first hospital admission. There are a number of cases reported where colitis had been a significant feature of the disease ${ }^{5-8}$ many years after initial diagnosis. However, there have been very few cases reported where colitis seemed to be the only presenting feature..$^{9-11}$ In this case, the patient had experienced sinus congestion and two episodes of epistaxis earlier but colitis was the reason for the first presentation to hospital. Owing to the absence of an infective cause and the temporal nature of the renal and pulmonary involvement leading to diagnosis, this case is likely to represent one of the few where colitis was the primary reason for presentation.

At the second admission the diagnosis of WG was much easier to make because there was renal involvement. It is unfortunate in terms of this case report and scientific curiosity that a complete colonoscopy was not performed. It would have been significant to see the character of the mucosa and examine the histology in the right colon which appeared inflamed on CT.
However, it may be the case that histological findings would have been non-specific. ${ }^{12}$

Steroid and cyclophosphamide therapy was started following the BSR guidelines ${ }^{13}$ and the patient's renal function and symptoms improved. The patient is now in remission.

WG potentially has very serious complications and thus a diagnosis should not be delayed. There should be a high level of suspicion in case of patients with colitis where the cause is unclear and cANCA plus PR3 tests should be performed. A urine dip at admission may have also been useful.

The primary interest in this case is the unusual presentation. WG should be considered in unusual cases of colitis with a positive cANCA. A history of sinusitis or renal involvement should certainly add to suspicion.

\section{Learning points}

- Wegener's granulomatosis (WG) should be considered as a cause for colitis in unusual cases or cases where there are other signs and symptoms such as sinusitis, haemoptysis or impaired renal function.

- A positive antineutrophil cytoplasmic antibodies (CANCA) in a case of colitis may indicate WG and a PR3 screen should be undertaken, a urine dip be performed and a chest x-ray may be considered.

- Early diagnosis of WG when it presents before renal involvement may help patients avoid more invasive procedures and treatments.

Competing interests None.

Patient consent Obtained.

Provenance and peer review Not commissioned; externally peer reviewed.

\section{REFERENCES}

1 Wegener $F$. Uber eine eigenartige rinogene granulomatose mit besonderer, beteiligung des arteriensystems und der Nieren. Beitr Path Anat Pathol 1939; 102:36-68.

2 Fauci AS, Haynes BF, Katz P, et al. WG: prospective clinical and therapeutic experience 85 patients for 21 years. Ann Intern Med 1983;98:76-85.

3 Anderson G, Coles ET, Crane M, et al. WG granuloma. A series of 265 British cases seen between 1975 and 1985. A report by a sub-committee of the British Thoracic Society Research Committee. Q J Med 1992;83:427-38.

4 Hoffman GS, Kerr GS, Leavitt RY, et al. WG: an analysis of 158 patients. Ann Intern Med 1992;116:488-98.

5 Deniz K, Ozseker HS, Balas S, et al. Intestinal involvement in Wegener's granulomatosis. J Gastrointestin Liver Dis 2007;16:329-31.

6 Akca T, Colak T, Caglikulekci M. Intestinal perforation in Wegener's granulomatosis. Turk J Trauma Emerg Surg 2005;11:348-51.

7 Shaikh F, Sabu C, Peirce T, et al. Extensive intestinal ischaemic necrosis in Wegener's granulomatosis. Gut 55:1368-9.

8 Storesund B, Gran JT, Koldingsnes W. Severe intestinal involvement in Wegener's granulomatosis: report of two cases and review of the literature. $\mathrm{Br} J$ Rheumatol 1998;37:387-90.

9 Schneider A, Menzel J, Gaubitz M, et al. J Intern Med 1997;242:513-17.

10 Steel C, Bohra S, Broe P, et al. Acute upper gastrointestinal haemorrhage and colitis: an unusual presentation of Wegener's granulomatosis. Eur J Gastroenterol Hepatol 2001;13:993-5.

11 Qian Q, Cornell L, Chandran V, et al. Haemorrhagic colitis as a presenting feature of Wegener granulomatosis. J Gastrointestin Liver Dis 2010;19:445-7.

12 Muller-Lander U, Vasculitides of the gastrointestinal tract. Best Pract Res Clin Gastroenterol 2001;15:59-82.

13 Lapraik C, Watts R, Bacon P, et al. BSR and BHPR guidelines for the management of adults with ANCA associated vasculitis. Rheumatology 2007:46:1-11. 
Copyright 2013 BMJ Publishing Group. All rights reserved. For permission to reuse any of this content visit http://group.bmj.com/group/rights-licensing/permissions.

BMJ Case Report Fellows may re-use this article for personal use and teaching without any further permission.

Become a Fellow of BMJ Case Reports today and you can:

- Submit as many cases as you like

- Enjoy fast sympathetic peer review and rapid publication of accepted articles

- Access all the published articles

- Re-use any of the published material for personal use and teaching without further permission

For information on Institutional Fellowships contact consortiasales@bmjgroup.com

Visit casereports.bmj.com for more articles like this and to become a Fellow 